\title{
Role of platelet-activating factor (PAF) in the initiation of the decidual reaction in the rat
}

\author{
G. Acker, P. Braquet* and J. M. Mencia-Huerta* \\ INSERM U 187, 32 rue des Carnets, 92140 Clamart, France; and ${ }^{*}$ I.H.B. Research Laboratories, \\ 1 avenue des Tropiques, 91952 Les Ulis, France
}

\begin{abstract}
Summary. Injection of PAF into the left uterine horn induced a dose-dependent decidua-like reaction in the pseudopregnant rat. This reaction was maximal when PAF was injected at Day 5 of pseudopregnancy and was blocked by the specific PAF antagonist, BN 52021. BN 52021 did not interfere with the decidual reaction induced by prostaglandin E-2 or insertion of a cotton thread in the uterine horn. In contrast, a decidua-like reaction was not evoked by the inactive lyso-PAF, demonstrating the specificity of the action of PAF. The decidua-like reaction induced by PAF involves the generation of cyclooxygenase metabolites of arachidonic acid since it was inhibited by indomethacin. The histological alterations induced by PAF were similar to those observed after embryo implantation, strengthening the postulate for a role of the autacoid in the early stages of pregnancy.
\end{abstract}

Keywords: decidual reaction; platelet-activating factor; prostaglandin; implantation; rat

\section{Introduction}

The differentiation of uterine stroma cells into decidual cells occurs in the pregnant rat during the implantation of blastocysts (Finn, 1971). A similar decidual cell reaction (DCR) can be elicited in the pseudopregnant rat by application of an artificial stimulus such as local scraping or oil introduction in the lumen of the uterus (Finn \& Keen, 1962). Since the inhibitor of the cyclooxygenase enzyme, indomethacin, when injected systemically or into the uterine horn inhibits the DCR, a major role for prostaglandins (PG) in this process has been suggested (Castracane et al., 1974; Sananes et al., 1976). Indeed, this effect of indomethacin is partly reversed by PGF- $2 \alpha$ which, like PGE-2, is able to induce the DCR in rats (Lau et al., 1973; Kennedy, 1986). However, the precise mechanism(s) of action of PG in initiation of the DCR is unknown although an increase in the vascular permeability of blood vessels (Kennedy, 1977) and a direct effect on the rate of DNA synthesis (Peleg \& Lindner, 1980) have been proposed to explain their effects.

Recently, various mediators have been described that may be implicated in the initial vasopermeation and vasodilatation involved in the DCR. Among these mediators, platelet-activating factor (PAF) and leukotrienes exhibit vasomotor properties (Drazen et al., 1980; Lewis \& Austen, 1981; Pirotzky et al., 1984). In addition, the involvement of PAF in implantation has been suggested since this mediator exhibits the biological activity of 'early pregnancy factor' ( $O$ 'Neill, 1985; Orozco et al., 1986) and is present in increased concentrations in the rabbit uterus during the early phase of gestation (Angle et al., 1985). PAF has been proposed as the first embryonic signal and its role in the early events of the implantation process has been demonstrated using a pharmacological approach. In independent studies, two unrelated PAF antagonists, L-653,761 (Spinks \& O'Neill, 1987) and BN 52021 (Acker et al., 1988) have been shown to inhibit implantation in the rat and the mouse, respectively. 
In the rat, as in all other mammalian species, ovum implantation is preceded at the sites where blastocysts are present by an increase in endometrial vascular permeability which is thought to be essential for the subsequent development of the DCR (Psychoyos, 1973). Since PAF generation has been proposed as the primary signal originating from the embryo, the possibility that this phospholipid mediator could induce the development of a DCR in rats was investigated. In addition, the possible role of cyclooxygenase-derived arachidonic acid metabolites as secondary messengers in this process was also analysed.

\section{Materials and Methods}

Drugs. The following substances were obtained as noted: PAF (1-hexadecyl-2-acetyl-sn-glyceryl-3-phosphorylcholine) was from Novabiochem (Strasbourg, France); lyso-PAF from Novabiochem; BN 52021, a specific PAF antagonist (Braquet et al., 1985, 1987) was from I.H.B. Res. Laboratories (Le Plessis-Robinson, France); indomethacin, a cyclooxygenase blocker, and PGE-2 were from Sigma (St Louis, MO, USA). Sesame oil was obtained from Coopération Pharmaceutique Française (Paris, France), PAF and lyso-PAF were dissolved in phosphatebuffered saline solution (PBS) containing $0.25 \%$ bovine serum albumin (Sigma) (PBS-BSA). BN 52021 was initially dissolved in dimethylsulphoxide (DMSO) and further diluted in PBS to the appropriate concentration. The concentration of DMSO in the injected solution containing BN 52021 never exceeded $0 \cdot 1 \%(\mathrm{v} / \mathrm{v})$. This highest concentration of DMSO used did not interfere with the experiments.

Experimental protocol. Wistar female rats weighing 180-200 g (Janvier, Le Genest, France) were used throughout the experiments. Day 1 of gestation was defined by the presence of copulatory plugs and spermatozoa in the vaginal tract. Pseudopregnancy was achieved by sectioning the oviducts on both sides on Day 1. After 3-6 days of pseudopregnancy, a total volume of $100 \mu \mathrm{l}$ of the solution(s) containing the various substances, either alone or in combination, or the solvent alone was injected into the left uterine horn.

Evaluation of the DCR. Animals were killed 5 days after the intrauterine injection. The left and right horns were removed and cleaned of fatty tissue, weighed and placed in Bouin's solution. The entire tissue was embedded in paraffin wax and cut in a series of transverse sections $(7 \mu \mathrm{m})$. Each 20 th section was fixed and stained by the Masson trichrome technique. Histological quantitation of the decidualization process was made as previously described (Alloiteau \& Acker, 1962).

\section{Results}

\section{Effect of intrauterine administration of PAF at Day 5 of pseudopregnancy}

As assessed by measuring the wet weight of the left uterine horn, intrauterine injection of the solvent of PAF induced in $27 \cdot 2 \%$ of the rats a local decidua-like reaction at the precise site of injection. This reaction was always of limited extent since only a minimal increase in the wet weight of the left horn was noted, as compared to the average weight of the untreated right horns (Fig. 1). In contrast, injection of PAF resulted in $100 \%$ of the treated rats exhibiting a dose-dependent increase in the wet weight of the left uterine horn, up to a maximum reached with $1 \mu \mathrm{g}$ PAF (Fig. 1). The maximal response to $1 \mu \mathrm{g}$ PAF was about $75 \%$ of the DCR induced by injection of $100 \mu 1$ sesame oil that reached $1473 \pm 33 \mathrm{mg}$ in 4 experiments.

\section{Kinetics of administration of PAF in the left uterine horns of pseudopregnant rats}

In the next series of experiments the dose of $1 \mu \mathrm{g}$ PAF was chosen since it induced a maximal response. In these experiments, PAF was injected at Day 3, 4, 5 or 6 of pseudopregnancy. A maximal increase in the wet weight of the left uterine horn was obtained when PAF was injected at Day 5. Indeed, all rats $(N=8)$ injected at Day 5 presented a decidua-like reaction and the average wet weight of the left uterine horn was $1125.5 \pm 194.0 \mathrm{mg}$. Injection of PAF at Day 4 or 6 resulted in a lesser reaction associated with an increase in the wet weight of the left uterine horn of $340.0 \pm 192.6 \mathrm{mg}(\mathrm{N}=5)$ and $414.2 \pm 290.5 \mathrm{mg}(\mathrm{N}=5)$, respectively. Administration of PAF at Day 3 of pseudopregnancy did not induce alteration in the wet weight of the left uterine horns (average weight $114.2 \pm 17.7 \mathrm{mg} ; \mathrm{N}=4$ ) as compared to the untreated right ones $(222 \cdot 2 \pm 191 \cdot 6 \mathrm{mg} ; \mathrm{N}=22)$. 


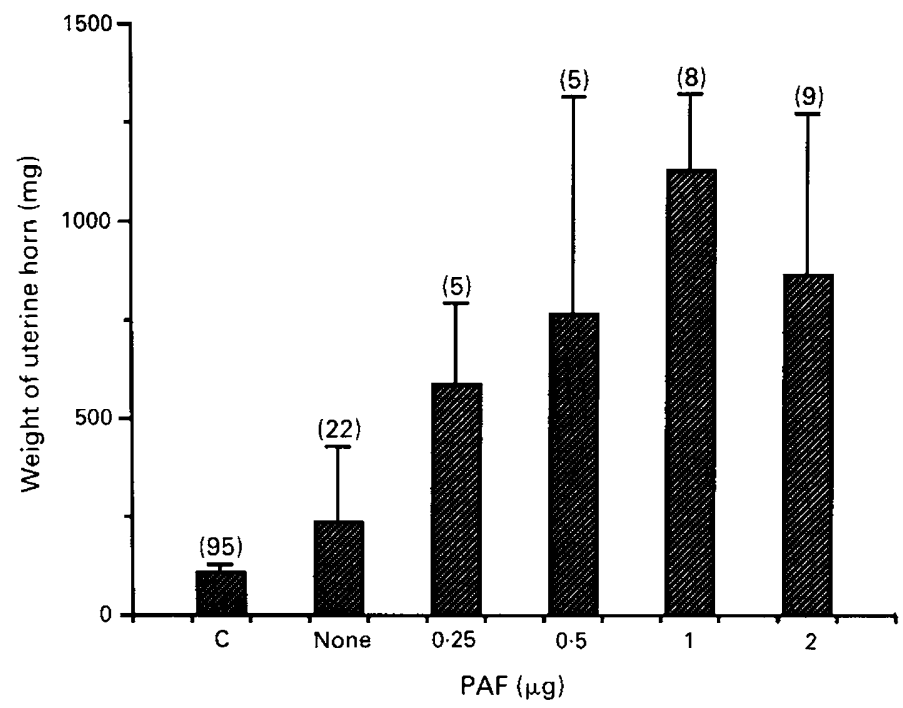

Fig. 1. Dose-dependent effect of intrauterine injection of PAF in the rat, 5 days after the initiation of pseudopregnancy. The animals were killed 5 days after the injection and the wet weight of the right (C) and left uterine horns was determined. Values are means \pm s.d. for the number of animals indicated in parentheses.

\section{Specificity of the effect of administration of PAF in the left uterine horns of pseudopregnant rats}

The specificity of the effect of PAF was checked by use of the inactive precursor and catabolite of PAF, namely lyso-PAF, and of the specific PAF antagonist, BN 52021 (Braquet et al., 1985, 1987). Injection of $1 \mu \mathrm{g}$ lyso-PAF resulted in a moderate increase in the wet weight of the left uterine horn in only $50 \%$ of the treated animals (Table 1). When a dose of $2 \mu \mathrm{g}$ lyso-PAF was injected, $100 \%$ of the rats exhibited an increase in the wet weight of the treated uterine horn, but the affected area was still of limited extent.

Table 1. Effect of intrauterine injection of PAF or lyso-PAF at Day 5 of pseudopregnancy in the rat

\begin{tabular}{|c|c|c|}
\hline Treatment & $\begin{array}{l}\% \text { Rats with } \\
\text { DCR }\end{array}$ & $\begin{array}{l}\text { Weight of } \\
\text { the left horn } \\
\text { (mg) }\end{array}$ \\
\hline Solvent alone & 27 & $233.9 \pm 191.6(22)$ \\
\hline PAF, $1 \mu \mathrm{g}$ & 100 & $1125.5 \pm 194.0$ \\
\hline $\mathrm{PAF}, 2 \mu \mathrm{g}$ & 100 & $864.8 \pm 405.9$ \\
\hline Lyso-PAF, $1 \mu \mathrm{g}$ & 50 & $431 \cdot 1 \pm 300 \cdot 7$ \\
\hline Lyso-PAF, $2 \mu \mathrm{g}$ & 100 & $374.6 \pm 28.6$ (5) \\
\hline
\end{tabular}

Values are means \pm s.d. of the values for the number of animals indicated in parentheses.

In the next series of experiments, a dose of $10 \mathrm{nmol}$ BN 52021 was used since it has previously been shown to be optimal in preventing implantation in the rat (Acker et al., 1988). After concomitant injection of $0.5 \mu \mathrm{g}$ PAF and of BN 52021, no notable increase in the wet weight of the treated left uterine horn was noted, as compared to the values obtained in the absence of the antagonist (Table 2). However, in $50 \%$ of the rats treated with BN 52021 a decidua-like reaction of very 
limited extent was observed. When $1 \mu \mathrm{g}$ PAF was injected concomitantly with BN 52021, a moderate decidua-like reaction was observed in $80 \%$ of the animals. This is also reflected by the slight increase in the average wet weight of the left uterine horn (Table 2).

Table 2. Effect of BN $52021(10 \mathrm{nmol})$ on the decidua-like reaction induced by intrauterine injection of PAF at Day 5 of pseudopregnancy in the rat

\begin{tabular}{|c|c|c|}
\hline Treatment & $\begin{array}{c}\% \text { Rats with } \\
\text { DCR }\end{array}$ & $\begin{array}{l}\text { Weight of the } \\
\text { left uterine horn } \\
(\mathrm{mg})\end{array}$ \\
\hline $\begin{array}{l}\text { PAF, } 0.5 \mu \mathrm{g} \\
\text { PAF, } 0.5 \mu \mathrm{g}+ \\
\text { BN } 52021 \\
\text { PAF, } 1.0 \mu \mathrm{g} \\
\text { PAF, } 1.0 \mu \mathrm{g}+ \\
\text { BN } 52021\end{array}$ & $\begin{array}{r}50 \\
100\end{array}$ & $\begin{array}{r}763.2 \pm 546.6(5) \\
266.5 \pm 140.0(5) \\
1125.5 \pm 194.0(8)\end{array}$ \\
\hline
\end{tabular}

Values are means \pm s.d. of the values for the number of animals indicated in parentheses.

In another series of experiments, the effect of $10 \mathrm{nmol} \mathrm{BN} 52021$ on the DCR induced by $80 \mu \mathrm{g}$ PGE-2 injected into the left uterine horn was investigated. No effect of the PAF antagonist was noted since the increase in the wet weight of the left uterine horn induced by PGE-2 was similar in BN 52021-treated and control rats. In addition, BN 52021 did not affect the DCR induced by the insertion of a cotton thread in the left horn since no changes in the wet weight were noted in $\mathrm{BN}$ 52021-treated and control animals (data not shown).

Pharmacological modulation of the decidua-like reaction induced by PAF in the left uterine horns of pseudopregnant rats

In some experiments, the possible implication of PG generation in the effect of $1 \mu \mathrm{g}$ PAF was investigated. Injection of the cyclooxygenase blocker, indomethacin $(10 \mathrm{nmol})$, impaired the development of the decidua-like reaction induced by PAF since no changes in the wet weight of the left uterine horn were observed. This dose of indomethacin has been previously shown to prevent implantation in the rat (Lau et al., 1973; Acker et al., 1988).

Histological alterations induced by administration of PAF in the left uterine horns of pseudopregnant rats

In selected experiments, histological examination of solvent- and PAF- $(0.5$ and $1 \mu \mathrm{g})$ treated horns revealed alterations in the latter of the endometrium consistent with the development of a DCR (Fig. 2). In the PAF-treated horns, general oedema in the endometrium and focal (antimesometrial) DCR were observed. In addition, hyperplasia and hypertrophy of the endometrium with the occurrence of some binucleated cells were noted. These alterations induced by 0.5 or $1 \mu \mathrm{g}$ PAF were similar to those observed at the site of embryo implantation (data not shown).

\section{Discussion}

The present results demonstrate that synthetic PAF induces a local inflammatory reaction when injected into the left uterine horn of pseudopregnant rat. This reaction, as assessed by the increase 

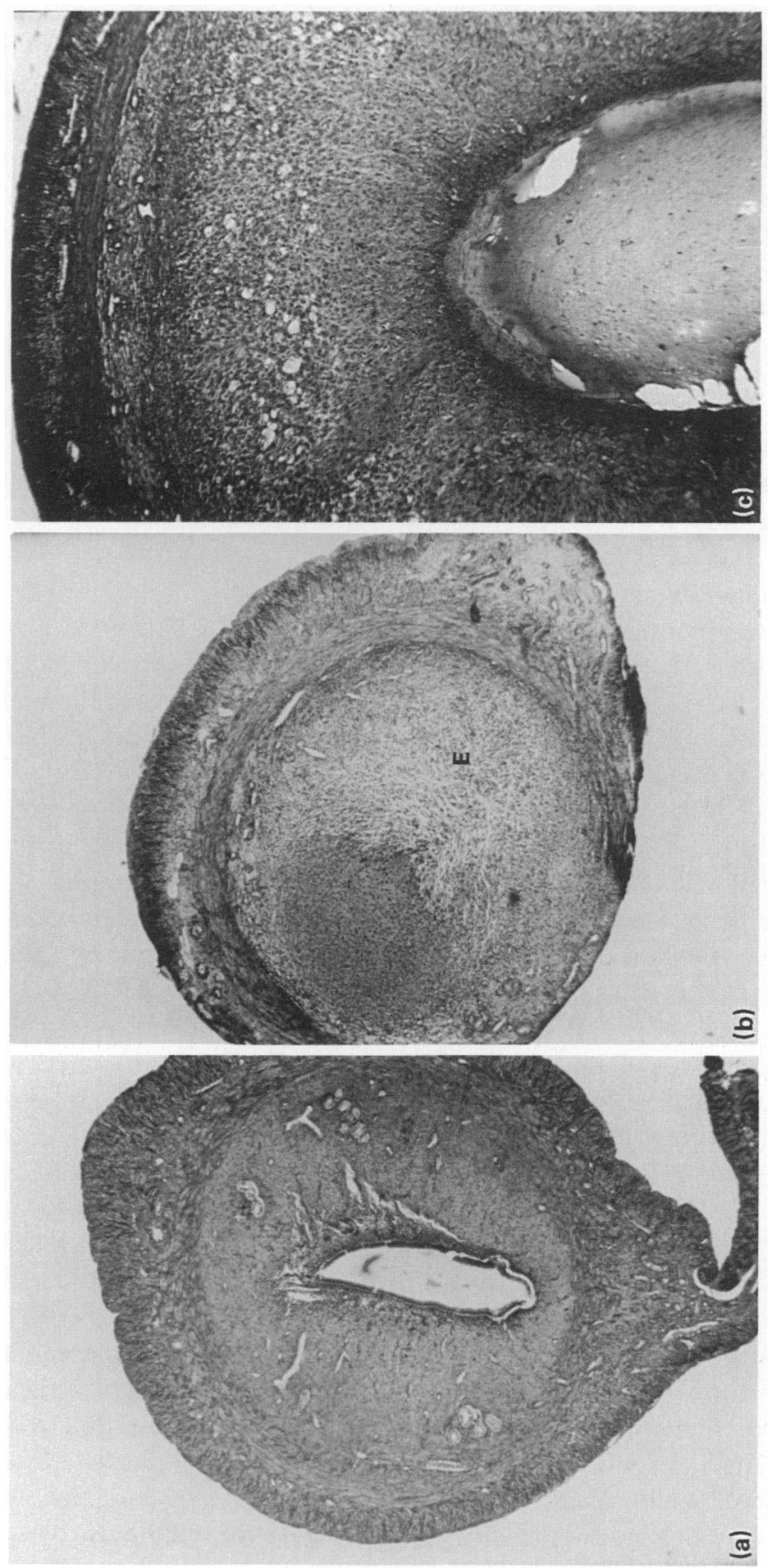

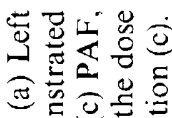

$>0$ on

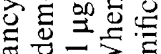

艺

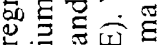

응

$\because$ E

象 일

乞 म

○ 000

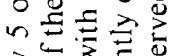

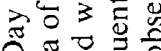

口.

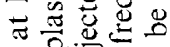

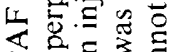

스음

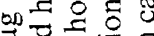

二要焉

b $2 \cdot \overline{1}$

的空吉巳

$\dot{0} \Xi \approx \frac{1}{2}$

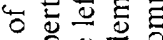

ᄃ 20

오웡

过芯芯

舟导焉

U巳

.

总诘

苟官范它

至 수욜

풍 㐘 远造号 氖芯导

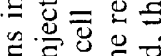
ธ. 吉总

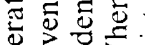
肎 苞官完 का 0 \% 잉요

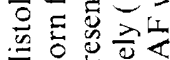

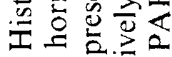
․ㅛ

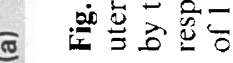


in the wet weight of the left horn, is maximal when a dose of $1 \mu \mathrm{g}$ PAF is administered at Day 5 of pseudopregnancy. As previously demonstrated (De Feo, 1963), this time point corresponds to the maximum sensitivity of the uterus in response to chemical stimulation or trauma. In addition, in agreement with the work of De Feo (1963) who used chemical inducers or scratch trauma, the response to intrauterine injection of PAF is markedly reduced when the phospholipid mediator is given after 4 or 6 days of pseudopregnancy. This result excludes the possibility that PAF evokes a non-specific inflammatory reaction, regardless of the preparation of the endometrium by sexual hormones. In addition, the moderate action, if any, of lysoPAF, which has no biological activity, excludes a non-specific irritation of the uterus by the lipid.

The decidua-like reaction induced by PAF is observed all along the uterine horn and this is in contrast with what is noted after implantation in the rat when the DCR occurs only at the site of embryo implantation. This result, however, is consistent with the hypothesis that PAF is the initial signal released by the murine embryo ( $\mathrm{O}^{\prime} \mathrm{Neill}, 1985$ ) since in our experiments the solution containing the mediator probably fills the entire uterine lumen and evokes a generalized reaction. This does not apply to the embryo that may bear the PAF (or PAF-like molecules) associated with the cell surface and thus induces a reaction of limited extent.

The effect of PAF on the uterus is inhibited by the PAF antagonist, BN 52021, used at a dose previously shown to inhibit implantation in the rat (Acker et al., 1988). This drug, however, failed to interfere with the DCR induced by PGE-2 or insertion of a cotton thread in the left uterine horn, demonstrating its specificity of action. BN 52021 not only markedly decreases the intensity of the reaction, as assessed by measuring the wet weight of the horns, but also reduces the number of rats presenting a positive reaction after PAF injection.

Histological examination of the uterine horns after PAF administration demonstrated morphological alterations similar to those observed at the site of embryo implantation in the rat (Loeb, 1908). Indeed, the presence of oedema associated with hypertrophy and hyperplasia of endometrial cells is characteristic of the DCR. In addition, numerous binucleated cells were present following PAF administration, as well as after embryo implantation or DCR induced by chemical agents or trauma (De Feo, 1967). It therefore appears that PAF induces a true DCR and not only an inflammatory reaction.

In the present study, the effect of intrauterine injection of PAF was inhibited by the cyclooxygenase blocker, indomethacin. This result is in keeping with the well established role of these arachidonic acid metabolites in both ovoimplantation and the DCR (Lau et al., 1973; Castracane et al., 1974; Acker et al., 1988). This is also confirmed by the work of Kennedy (1986) who demonstrated that PGE-2 induces a DCR in the rat. PAF has been previously shown to recruit arachidonic acid metabolism by the cyclooxygenase pathway leading to the generation of PGE-2 by various cell types or tissues (Shaw et al., 1981; Schlondorf et al., 1984; Billah et al., 1985). More recently, PAF has been shown to increase the release of PGE-2 from human endometrium (Smith \& Kelly, 1988). It is therefore tempting to speculate that the effects of PAF are only mediated via the generation of PG by cells of unidentified origin, whose consequence is induction of the DCR. The fact that the PAF antagonist, BN 52021, did not interfere with the DCR evoked by PGE-2 or cotton thread further strengthens the hypothesis that the drug acts only at the PAF receptor level and not on a later event. The DCR induced by non-specific stimuli such as a cotton thread is believed to be mediated by arachidonate metabolites and the lack of effect of BN 52021 in this process suggests that their generation is not due to the local formation of PAF. Finally, since leukotrienes have been postulated to play a role in the DCR (Malathy et al., 1986; Sagrillo et al., 1987) and are perhaps generated after stimulation with PAF (Chilton et al., 1982; Piper \& Stewart, 1986), the relationship between the various arachidonic acid metabolites generated by PAF and the success of ovoimplantation deserves investigation. 


\section{References}

Acker, G., Hecquet, F., Etienne, A., Braquet, P. \& Mencia-Huerta, J.M. (1988) Role of platelet-activating factor (PAF) in the ovoimplantation in the rat: effect of the specific PAF antagonist, BN 52021. Prostaglandins 35, 233-241.

Alloiteau, J.J. \& Acker, G. (1962) Deciduomes traumatiques après préparation progestéronique de courte durée chez la ratte. C. r. Séanc. Soc. Biol. 160, $480-483$

Angle, M.J., Jones, M.A., Pinckard, R.N., Mc Manus, L.M. \& Harper, M.J.K. (1985) Platelet-activating factor (PAF) in the rabbit uterus during early pregnancy. Biol. Reprod. 32 (Suppl. 1), 143, Abstr.

Billah, M.M., DiRenzo, G.C., Ban, C., Truong, C.T., Hoffman, D.R., Anceschi, M.M., Bleasdale, J.E. \& Johnston, J.M. (1985) Platelet-activating factor metabolism in human amnion and the responses of this tissue to intracellular platelet-activating factor. Prostaglandins 30, 841-851.

Braquet, P., Spinnewyn, B., Braquet, M., Bourgain, R.H., Lefort, J. \& Vargaftig, B.B. (1985) BN 52021 and related compounds: a new series of highly specific PAF-acether receptors antagonists isolated from Ginkgo biloba. Blood and Vessels 16, 559-562.

Braquet, P., Touqui, L., Shen, T.Y. \& Vargaftig, B.B. (1987) Perspectives in platelet-activating factor research. Pharmac. Rev. 39, 97-145.

Castracane, V.D., Saksena, S.K. \& Shaikh, A.A. (1974) Effect of IUDs, Prostaglandins and indomethacin on the decidual cell reaction in the rat. Prostaglandins 6, 397-405.

Chilton, F.M., O'Flaherty, J.T., Walsh, C.E., Thomas, M.J., Wykle, R.L., DeChatelet, L.R. \& Waite, B.M. (1982) Platelet-activating factor stimulation of the lipoxygenase pathway in polymorphonuclear leukocytes by 1-0-alkyl-2-acetyl-sn-glycero-3-phosphocholine. J. biol. Chem. 257, 5402-5407.

De Feo, V.J. (1963) Determination of the sensitive period for the induction of deciduomata in the rat by different inducing procedures. Endocrinology 73, 488-497.

De Feo, V.J. (1967) Decidualization. In Cellular Biology of the Uterus, pp. 191-290. Ed. R. M. Wynn. Appleton Century-Crofts, New York.

Drazen, J.M., Austen, K.F., Lewis, R.A., Clark, D.A., Goto, D.A., Marfat, A. \& Corey E.J. (1980) Comparative airways and vascular activities of leukotrienes $\mathrm{C}-1$ and D in vitro and in vivo. Proc. natn. Acad. Sci. USA $77,4354-4359$.

Finn, C.A. (1971) The biology of decidual cells. Adv. Reprod. Physiol. 5, 1-16.

Finn, C.A. \& Keen P.M. (1962) Studies on deciduomata formation in the rat. J. Reprod. Fert. 4, 215-216.

Kennedy, T.G. (1977) Evidence for a role for prostaglandins in the initiation of blastocyst implantation in the rat. Biol. Reprod. 16, 286-293.

Kennedy, T.G. (1986) Intra-uterine infusion of prostaglandins and decidualization in rat with uterine differentially sensitized for the decidual cell reaction. Biol. Reprod. 34, 327-337.

Lau, I.F., Saksena, S.K. \& Chang, M.C. (1973) Pregnancy blockade by indomethacin, an inhibitor of prostaglandin synthesis: its reversal by prostaglandins and progesterone in mice. Prostaglandins 4, 795-805.
Lewis, R.A. \& Austen, K.F. (1981) Mediation of local homeostasis and inflammation by leukotrienes and other mast cell-dependent products. Nature, Lond. 293, 103-108.

Loeb, L. (1908) The production of deciduomata and the relation between the ovaries and the formation of the decidua. J. Am. med. Assoc. 50, 1897-1901.

Malathy, P.V., Cheng, H.C. \& Dey, S.K. (1986) Production of leukotrienes and prostaglandins in the rat uterus during periimplantation period. Prostaglandins 32, 605-614.

O'Neill, C. (1985) Examination of the cause of early pregnancy-associated thrombocytopenia in mice. $J$. Reprod. Fert. 73, 567-577.

Orozco, C., Perkins, T. \& Clarke, F.M. (1986) Plateletactivating factor induces the expression of early pregnancy factor activity in female mice. J. Reprod. Fert. 78, 549-555.

Peleg, S. \& Lindner, H.R. (1980) Role of steroid hormones and prostaglandins in the regulation of DNA synthesis by decidual cells in culture. Molec. cell. Endocrinol. 20, 209-218.

Piper, P.J. \& Stewart A.G. (1986) Coronary vasoconstriction in the rat isolated perfused heart induced by platelet-activating factor is mediated by leukotriene $\mathrm{C}_{4}$. Br. J. Pharmacol. 88, 595-605.

Pirotzky, E., Page, C.P., Roubin, R., Pfister, A., Paul, W., Bonnet, J. \& Benveniste, J. (1984) Paf-acether-induced plasma exudation in rat skin is independent of platelets and neutrophils. Microcirc. Endothel. Lympho. 1, 107-113.

Psychoyos, A. (1973) Endocrine control of egg implantation. In Handbook of Physiology, Vol. II, pp. 187-215. Eds R. O. Greep, E. G. Astwood \& S. R. Geiger. American Physiological Society, Washington DC.

Sagrillo, C., Tawfik, O.W., Johnson, D.C. \& Dey, S.K. (1987) Leukotrienes are necessary for decidualization in the rat. Biol. Reprod. 36 (Suppl. 1), 330, Abstr.

Sananes, N., Baulieu, E.E. \& Le Goascogne, C. (1976) Prostaglandin(s) as inductive factor of decidualization in the rat uterus. Molec. cell. Endocrinol. 6, 153-160.

Schlondorff, D., Satriano, J.A., Hagege, J., Perez, J. \& Band, L. (1984) Effect of platelet-activating factor and serum-treated zymosan on prostaglandin $\mathbf{E}_{2}$ synthesis, arachidonic acid release and contraction of cultured rat mesangial cells. J. clin. Invest. 73, 1227-1231.

Shaw, J.O., Klusick, S.J. \& Hanahan, D.J. (1981) Activation of rabbit platelet phospholipase and thromboxane synthesis by 1-0-hexadecyl/octadecyl-2acetyl-sn-glyceryl-3-phosphocholine (platelet-activating factor). Biochim. Biophys. Acta 663, 222-229.

Smith, S.K. \& Kelly, R.W. (1988) Effect of plateletactivating factor on the release of PGF-2 and PGE-2 by separated cells of human endometrium. J. Reprod. Fert. 82, 271-276.

Spinks, N.R. \& O'Neill C.O. (1987) Embryo-derived Platelet-Activating Factor is essential for establishment of pregnancy in the mouse. Lancet 106, 106-107.

Received 25 July 1988 